\title{
HISTÓRIAS DE VIDA DE IMIGRANTES PORTUGUESES NO RIO DE JANEIRO
}

\author{
MIRIAM DE OLIVEIRA SANTOS \\ https://orcid.org/0000-0001-9177-2417 \\ Universidade Federal Rural do Rio de Janeiro
}

RESUMO O objetivo deste artigo é analisar histórias de vida de imigrantes portugueses estabelecidos na zona rural da cidade do Rio de Janeiro. A metodologia utilizada foram as entrevistas não estruturadas, nas quais os entrevistados foram escolhidos através da técnica da bola de neve e, por questão de espaço, trabalharemos neste artigo apenas duas entrevistas exemplares. Concluímos que as histórias de vida desses imigrantes nos permitem descortinar uma série de dados importantes sobre uma imigração pouco estudada.

Palavras-chave: Biografias. História de vida. Imigração.

\section{ABSTRACT LIFE STORIES OF PORTUGUESE IMMIGRANTS IN RIO DE JANEIRO}

The objective of this article is to analyze life histories of Portuguese immigrants established in the rural area of the Rio de Janeiro city. The methodology used was unstructured interviews, in which the interviewees were chosen using the snowball technique and for spatial reasons, we will work on this article with just two exemplary interviews. We conclude that the life stories of these immigrants allow us to unveil a series of important data about a little studied immigration. Keywords: Biography. Life's history. Immigration.

\section{RESUMEN HISTORIAS DE VIDA DE INMIGRANTES PORTUGUESES EN RIO DE JANEIRO}

El objetivo de este artículo es analizar las historias de vida de inmigrantes portugueses establecidos en el área rural de la ciudad de Río de Janeiro. La metodología utilizada fue entrevistas no estructuradas, los entrevistados fueron elegidos utilizando la técnica de bola de nieve $y$, por razones de espacio, trabajaremos en este artículo con solo dos entrevistas ejemplares. Concluimos que las historias de vida de estos inmigrantes nos permiten revelar una serie de datos importantes sobre una inmigración poco estudiada.

Palabras Clave: Biografias; Historia de vida; Inmigración. 


\section{Introdução}

Desde que Thomas e Znaniecki (1974) escreveram seu famoso trabalho utilizando cartas de imigrantes poloneses, a Antropologia se debruça sobre os pequenos registros da vida cotidiana: cartas, diários e até mesmo cardápios e receitas. No Brasil, várias famílias pagaram pela publicação de livros com a história de vida dos seus avós ou bisavós. No entanto, podemos observar que essa é uma produção extremamente concentrada em algumas etnias: alemães e judeus, sobretudo. Por outro lado, apesar de serem a maioria dos imigrantes históricos entrados no Brasil, portugueses e espanhóis possuem pouquíssimas biografias publicadas.

Nos últimos anos, com a popularização da história oral, vários depoimentos foram gravados e, especialmente no caso dos imigrantes, as entrevistas aconteciam com os mais idosos, buscando resolver também as lacunas deixadas pelo fato dos imigrantes de algumas nacionalidades terem chegado ao Brasil em grupos nos quais predominavam os analfabetos ou semialfabetizados. Neste artigo, busco analisar histórias de vida de imigrantes portugueses estabelecidos na zona rural da cidade do Rio de Janeiro.

\section{A escrita de si}

Podemos situar o início da reflexão sobre si e da necessidade de escrever sobre a própria vida no período iluminista. Até então, predominava uma visão holística da vida com a in-

1 Iluminismo foi o movimento cultural que se desenvolveu na Inglaterra, Holanda e França, nos séculos XVII e XVIII. Nessa época, o desenvolvimento intelectual, que vinha ocorrendo desde o Renascimento, deu origem às ideias de liberdade política e econômica defendidas pela burguesia. Os filósofos e economistas que difundiam estas ideias julgavam-se propagadores da luz e do conhecimento, sendo, por isso, chamados de iluministas. Dentre as principais características do Iluminismo, estava a valorização da razão, considerada o mais importante instrumento para se alcançar qualquer tipo de conhecimento. fluência da religião e o predomínio do coletivo, sobretudo da família e da comunidade, sobre os desejos do indivíduo.

O conceito de identidade aparece em diversos campos disciplinares, com significados ligeiramente diferentes em cada um desses campos. Por isso, costuma ser adjetivada, para deixar mais claro o sentido no qual se está utilizando o conceito, por exemplo: identidade étnica, identidade cultural, identidade social, identidade múltipla etc. Desse modo, a identidade pode ser construída de várias formas, incluindo as formas idealizadas. Assim, as tradições são apropriações do passado: utilizadas para refletir no presente uma ideia de comunhão e também para marcar pertencimentos (HOBSBAWM, 1997).

Nas autobiografias, a noção de identidade merece destaque, como podemos notar na definição de Carvalho (2003) transcrita abaixo:

O autorrelato pode ser tomado como um lócus privilegiado do encontro entre a vida íntima do indivíduo e sua inscrição numa história social e cultural. A biografia, ao tornar-se discurso narrado pelo sujeito autor e protagonista, instaura sempre um campo de renegociação e reinvenção identitária. (CARVALHO, 2003, p. 284)

Ou seja, mais que uma história de vida, a autobiografia fornece uma oportunidade de organizar a vida e dar sentido aos fatos vivenciados pelo autor, que é ao mesmo tempo protagonista e narrador. Contudo, é mais do que isso, porque proporciona, nos termos de Pollak, uma oportunidade de construir a imagem que quer projetar para os outros e para si próprio:

Se podemos dizer que, em todos os níveis, a memória é um fenômeno construído social e individualmente, quando se trata da memória herdada, podemos também dizer que há uma ligação fenomenológica muito estreita entre a memória e o sentimento de identidade. Aqui o 
sentimento de identidade está sendo tomado no seu sentido mais superficial, mas que nos basta no momento, que é o sentido da imagem de si, para si e para os outros. Isto é, a imagem que uma pessoa adquire ao longo da vida referente a ela própria, a imagem que ela constrói e apresenta aos outros e a si própria, para acreditar na sua própria representação, mas também para ser percebida da maneira como quer ser percebida pelos outros. (POLLAK, 1992, p. 5)

Memórias e identidades não são elementos fixos, mas representações e construções da realidade, fenômenos que são mais subjetivos do que objetivos. Como observou Gillis (1994), a noção de identidade depende da ideia de memória e vice-versa; baseia-se em um sentido de semelhança no tempo e no espaço que é sustentado pela lembrança. Enfim, podemos afirmar que memória e identidade são valores disputados e que, na construção das identidades coletivas, existe um trabalho permanente de enquadramento da memória: “Cada vez que uma memória está relativamente constituída, ela efetua um trabalho de manutenção, de coerência, de unidade, de continuidade, de organização" (POLLAK, 1992). ${ }^{2}$

Portanto, é importante estar atento para o que Bourdieu (1986) chama de “ilusão biográfica", ou seja, a ideia de que a vida seria coerente, um todo sem desvios.

Como nos diz Fausto (1997, p. 9), de certo modo, nós “' inventamos' o passado a partir do presente". Pode-se encontrar no passado todo um repertório de termos simbólicos para atualizá-los no presente, isto é, cria-se uma versão a posteriori que organiza e confere sentido a fatos e eventos isolados. Portanto, acreditamos que, da mesma maneira que Barth (1992) afirmou, podemos reiterar que o passado é uma dimensão do contemporâneo.

20 que explica, por exemplo, porque a imigração de tanoeiros portugueses para Caxias do Sul (RS) é pouquíssimo conhecida e também porque as memórias sobre o bairro alemão e o bairro português da cidade desapareceram da história oficial.
As autobiografias, cartas e relatos são incorporados aos estudos das ciências sociais principalmente com o advento da Escola de Chicago na década de 20 do século XX, sobretudo após a publicação do clássico The Polish peasant in Europe and America, de William Thomas e Florian Znaniecki, baseado na análise de correspondência e relatos biográficos de camponeses poloneses que imigraram para os Estados Unidos da América. Após certo declínio, o uso da metodologia de histórias de vida retornou com força no final dos anos 1970, sobretudo na França.

\section{Diários, cartas, autobiografias e biografias de imigrantes}

$\mathrm{Na}$ região sul do Brasil, especialmente nas áreas de imigração italiana e alemã no Rio Grande do Sul e em Santa Catarina, abundam trabalhos baseados nas memórias dos primeiros colonos e na história oral contada por seus descendentes. No caso da biografia de imigrantes, observamos que alguns grupos como judeus e alemães publicam muito mais que os outros.

Nos parece que escolarização e classe social são os fatores decisivos para isso. No caso dos imigrantes italianos, por exemplo, as biografias que encontramos são principalmente de industriais, como Ábramo Eberle e Matarazzo, tendo em vista que só recentemente os descendentes de imigrantes italianos das classes médias começam a publicar os diários e/ ou cartas de seus pais.

Battistel e Costa (1982) citam as "lembranças" de um imigrante que, tendo chegado ao Brasil com quatro anos, descreve, décadas mais tarde, as agruras dos primeiros tempos. É óbvio que tratam-se de histórias que ele ouviu dos membros mais velhos da família e incorporou como "memórias". É significativo que existam grandes discrepâncias entre as “me- 
mórias" desses imigrantes que aqui chegaram na primeira infância e as cartas e relatos de imigrantes adultos.

Novamente, recorremos a Fausto, que explicita:

Além disso, convém lembrar que as lembranças citadas são também veículo de outras lembranças, de antepassados e amigos já mortos. 0 veículo não é neutro, impregnando também as histórias ouvidas, com sua própria elaboração. (FAUSTO, 1997, p. 9)

Encontramos nesse trecho um fenômeno semelhante ao que Sayad observou entre os filhos de imigrantes argelinos nascidos na França: são os "imigrantes que jamais imigraram" (SAYAD, 1998, p. 71). Os descendentes dos imigrantes se veem como parte de um processo histórico compartilhado. As histórias da imigração são contadas e recontadas com o objetivo de marcar a epopeia.

Seyferth (2011) afirma que:

[...] olhar para os usos de identidades indicadoras de duplo pertencimento a partir da noção de 'grupo de interesse', tendo em vista a dinâmica da recriação contínua do pertencimento grupal por intermédio de novas experiências, mesmo quando os descendentes de imigrantes, por exemplo, já perderam a maior parte dos vínculos culturais que os distinguiam dos outros norte-americanos. A identidade (étnica) permite associar o indivíduo, ou o grupo, a um passado, uma raça, uma cultura compartilhada, suscita sentimentos de pertença, mas o interesse comum também une, permitindo laços concretos de comunidade. (SEYFERTH, 2011, p. 55)

Isso é verdade tanto para a biografia quanto para a história oral, mas o registro dos fatos através da escrita permite uma edição que é um pouco mais difícil no depoimento para a história oral. Contudo, é importante não esquecer que esse processo nem sempre é consciente. Como adverte Pollak: “A memória é seletiva. Nem tudo fica gravado. Nem tudo fica registrado" (POLLAK,1992, p. 4). A advertência de Pollak encontra eco em vários outros pesquisadores que trabalham com memória e história.

A história oral é um procedimento metodológico que busca, pela construção de fontes e documentos, registrar, através de narrativas induzidas e estimuladas, testemunhos, versões e interpretações sobre a História em suas múltiplas dimensões: factuais, temporais, espaciais, conflituosas, consensuais. Não é, portanto, um compartimento da história vivida, mas, sim, o registro de depoimentos sobre essa história vivida. (DELGADO, 2010, p.15)

Contudo, ao mesmo tempo que as histórias da imigração servem para marcar a epopeia dos imigrantes - ressaltando as dificuldades enfrentadas para chegar até ali - elas também servem de exemplo e orientação moral para os filhos e netos.

O início da biografia de um imigrante alemão no Rio Grande do Sul deixa bem claro esse propósito:

Grandes acontecimentos, grandes conquistas, realizações e coisas notáveis eu não tenho para registrar. Que meu passado simples, minhas modestas e bem intencionadas palavras, sugestões e exemplos sejam para minha família, meus filhos e seus descendentes, uma dedicatória. Que sirvam para suas recordações e seus conhecimentos, a que eles saberão dar grande valia e para alguns será uma amável leitura. (Pedro Wiltgen apud BRAUN, 2010, p. 110)

Ao recontar sua vida, o autor busca manter coerência entre a história narrada e os fatos históricos, escolhendo os fatos que representam aquilo que foi mais significativo para si mesmo e para a história que deseja narrar.

Como Bertaux, acreditamos que:

O conceito que nós propomos consiste em considerar que há história de vida desde o momento em que um sujeito conta a outra pessoa, investigador ou não, um episódio qualquer de sua experiência vivida. O verbo 'contar' (narrar) é aqui essencial: significa que a produção dis- 
cursiva do sujeito adotou uma forma narrativa. (BERTAUX, 2005, p. 36, tradução nossa) ${ }^{3}$

Assim, tanto autobiografias quanto histórias de vida são narrativas, produções discursivas sobre si e sobre a sua vida, impregnadas das memórias dos fatos vividos, das sensações, das histórias de familiares e conhecidos, dos valores morais e da conjuntura em que são narradas.

\section{As histórias de vida dos \\ imigrantes portugueses}

De acordo com Demartini (2001), os imigrantes provenientes de Portugal vinham de uma nação com sérios problemas na área educacional, em que o analfabetismo era muito elevado. Isso explica o pequeno número de biografias que encontramos entre os descendentes de imigrantes portugueses, apesar de seu grande número e da longevidade e constância do fluxo. ${ }^{4}$

Como toda imigração em grande escala e com um fluxo que ocorre ao longo de muitos anos, a imigração portuguesa não é homogênea. Mas podemos afirmar que na migração que começa em meados do século XX e se prolonga pelo menos até a década de 1970 tem na sua maioria migrantes econômicos de baixa escolaridade.

Vários estudos sobre a imigração portuguesa para o Brasil (BASSANEZI, 1995; COSTA LEITE, 2000; LEVY, 1974; MENEZES, 2000; NEVES, 2002) apontam para o fato de que ela é significativa

3 "El concepto que nosotros proponemos consiste em considerar que hay relato de vida desde el momento em que un sujeto cuenta a otra persona, investigador o no, un episodio cualquiera de su experiencia vivida. El verbo 'contar' (narrar) es aquí esencial: significa que la producción discursiva del sujeto ha adoptado una forma narrativa".

4 As exceções são os intelectuais que fogem da ditadura de Salazar e que, de uma maneira geral, veem-se como exilados e não como imigrantes. Sobre esse assunto, ver: SILVA, Douglas Mansur. A Oposição ao Estado Novo no Exílio Brasileiro (1956-1975). 1ạ Ed. Lisboa: Imprensa de Ciências Sociais, 2006. ao longo de todo o século XX. Esses imigrantes provinham, em sua maior parte dos Açores, da Ilha da Madeira e das províncias do Norte (Minho, Beira e Traz-os-Montes). Também é consensual que essa é uma imigração majoritariamente masculina, com baixa taxa de retorno e voltada predominantemente para áreas urbanas. Nesse contexto são raras as biografias e autobiografias, contudo a técnica de recolher histórias de vida permite que esses imigrantes também tenham suas trajetórias retratadas. Cabe ressaltar que tal técnica vem da história e, sobretudo, da história oral.

Nesse sentido, é importante assinalar que: "A História Oral também não é sinônimo de história de vida. História de vida pode ser considerado um relato autobiográfico, mas do qual a escrita - que define a autobiografia está ausente." (FREITAS, 2002, p. 21).

De maneira análoga, Pollak afirma que:

[...] a memória é um fenômeno construído. Quando falo em construção, em nível individual, quero dizer que os modos de construção podem tanto ser conscientes como inconscientes. 0 que a memória individual grava, recalca, exclui, relembra, é evidentemente o resultado de um verdadeiro trabalho de organização. (POLLAK, 1992, p. 4-5)

Posto isso, cabe destacar que tanto a memória do grupo quanto a memória familiar são geralmente narradas pelos mais idosos. Sendo assim, ao pesquisar sobre imigrantes portugueses na cidade do Rio de Janeiro, foi importante entrevistar os imigrantes mais idosos e buscar reconstruir com eles as suas histórias de vida.

Eu vim praqui em 49. Eu vim para a casa da minha irmã lá na serra. [...] Trabalhei muito, muito mesmo. E tou aqui... Eu ia para a roça trabalhar porque eu queria ir para a frente. ( A.S. 81 anos, agricultor)

Observamos que nesse depoimento a ênfase é no trabalho e na penosidade do trabalho. 
Mas não existe uma intenção clara de servir de exemplo para a posteridade. Pollak afirma que:

Se a memória é socialmente construída, é óbvio que toda documentação também o é. Para mim não há diferença fundamental entre fonte escrita e fonte oral. A crítica da fonte, tal como todo historiador aprende a fazer, deve, a meu ver, ser aplicada a fontes de tudo quanto é tipo. Desse ponto de vista, a fonte oral é exatamente comparável à fonte escrita. Nem a fonte escrita pode ser tomada tal e qual ela se apresenta. (POLLAK, 1992, p. 8)

Sendo assim, a biografia não seria necessariamente mais fidedigna que a história oral. Por meio da história oral, é possivel relacionar memória e identidade e abre a possibilidade para estudos que partem do tempo presente, de personagens vivos. Mais do que testemunhar um fato ou relatar trajetórias, as histórias orais permitem, por intermédio de suas narrativas, a compreensão do processo de seleção dos acontecimentos, de constituição de discursos e, assim, estabelecem condições para análises que extrapolam a simples constatação dos fatos. Além disso, as narrativas estão imersas em subjetividades e tornam-se importantes justamente pelo fato dos indivíduos não recordarem passivamente dos eventos, mas elaborarem seus relatos a partir do que lembram, por intermédio da memória.

Pierre Nora (1993), em sua teoria sobre lugares de memória, preconiza que nem tudo é lembrado, registrado, retido e que para lembrar é necessário, antes, esquecer.

O que nós chamamos de memória, é de fato, a constituição gigantesca e vertiginosa do estoque material daquilo que nos é impossivel lembrar, repertório insondável daquilo que poderíamos ter necessidade de lembrar. (NORA,1993, p. 15)

Nesse entendimento, a memória seria definida como uma representação do passado, uma forma de atualização temporal de deter- minado fato. A memória seria proporcionada por uma reconstrução que se dá tanto pelo emocional quanto pelo intelectual, resultando em uma representação seletiva de um passado individual inserido em um contexto social, seja ele familiar, escolar ou nacional. É a memória que cria as condições para o desenvolvimento do sentimento de continuidade e de coerência de uma pessoa ou de um grupo no seu processo de construção de identidade. Ou seja, é a memória que permite organizar a vida como uma trajetória coerente e consciente.

Para Bourdieu (1986), a história de vida pauta-se numa: “[...] sucessão longitudinal de eventos constitutivos da vida considerados como história em relação ao espaço social em que ocorre". Como um desdobramento dessa afirmação, ele conclui que devemos considerar a "noção de trajetória como a série de posições sucessivamente ocupadas por um mesmo agente (ou um mesmo grupo) num espaço em devir e sujeito a incessantes transformações" (BOURDIEU, 1986, p. 71). Ou seja, a noção de trajetória permite integrar a memória em uma dimensão temporal, descrevendo os deslocamentos do indivíduo no tempo e espaço ao longo da vida.

\section{Imigrantes madeirenses no Rio de Janeiro}

Depois da Segunda Guerra Mundial, a migração de agricultores madeirenses para a cidade do Rio de Janeiro deu origem a uma pequena comunidade de agricultores e comerciantes de nacionalidade portuguesa que, em sua maior parte, mantiveram o contato com a Itha da $\mathrm{Ma}$ deira através de cartas e/ou visitas à ilha.

É importante iluminar a multiplicidade de fatores que estão envolvidos no ato de migrar, que gera não só um deslocamento, mas também uma série de rupturas, tais como: de laços familiares, de grupos de pertinência, de costu- 
mes, valores, cultura, de relação de produção, dentre outros.

No entanto, as rupturas nunca são totais. Os imigrantes não deixam de ser o que eram antes de imigrar. A língua, a maneira de ver o mundo, os hábitos e outras coisas adquiridas na infância e na juventude continuam com os imigrados e não se perdem no processo de migração. Observamos nas nossas entrevistas que a relação com o local de nascimento se mantém e que a ligação com a identidade local e regional muitas vezes se sobrepõe à identidade nacional. 0 grupo entrevistado define-se como madeirense, apesar da sociedade abrangente identificá-los como “imigrantes portugueses".

A maioria mantém laços estreitos com a Ilha da Madeira, muitos chegaram ao Brasil através de cartas de chamada de parentes e amigos e, em mais de um caso, voltaram à Itha da Madeira quando ficaram viúvos para buscarem esposas dispostas a viajar com eles para o Brasil.

Os filhos, nascidos no Brasil, também se pensam como "portugueses" diferentes dos demais brasileiros e, em sua maior parte, viajaram até a Ilha da Madeira para conhecer suas raízes. Igualmente comum é o contato com parentes que saíram da llha da Madeira para outros lugares, como a Suiça. A circulação dos madeirenses e o reconhecimento dessa identidade como fundamental permitem que aqueles que imigraram para a Suiça venham passar férias no Brasil, ou que todos se encontrem em determinadas épocas do ano na Itha da Madeira.

A comunidade madeirense no Brasil é composta sobretudo por agricultores e pequenos comerciantes. Quanto à faixa etária, a maioria está acima dos 60 anos: possuem em média entre 60 e 90 anos. Moram na zona rural do Rio de Janeiro, em bairros de classe média baixa. Todos os entrevistados são imigrantes portugueses, que chegaram ao Brasil entre 1930 e
1960. Como metodologia da pesquisa, foram realizadas histórias de vida obtidas através de entrevistas em profundidade utilizando a técnica da bola de neve para a escolha dos entrevistados.

Para o presente artigo, optou-se por trabaIhar com apenas duas entrevistas, que sintetizam os pontos principais dos temas tratados pelo grupo e das características dessa migração. De maneira geral, tais entrevistados foram pensados como informantes privilegiados no sentido apontado por Foote Whyte (2005).

Foram realizadas ao todo 10 entrevistas com homens e mulheres oriundos da Itha da Madeira, todos com mais de 70 anos. A técnica utilizada foi a entrevista não estruturada. Realizamos também entrevistas complementares com os filhos e netos desses imigrantes para tentar entender melhor o contexto em que eles estavam inseridos, as recordações que traziam e a maneira como contavam as suas histórias.

\section{A Ilha da Madeira}

A Ilha da Madeira, oficialmente designada como Região Autônoma da Madeira é um território português dotado de autonomia política e administrativa. A Ilha da Madeira faz parte integral da União Europeia com o status de região ultraperiférica.

Na realidade, trata-se não de uma ilha, mas de um arquipélago em que apenas as duas ilhas maiores - da Madeira e do Porto Santo - são habitadas. Apesar de possuir uma densidade populacional superior à média de Portugal e mesmo da União Europeia, 75\% da população da ilha da Madeira habitam em apenas $35 \%$ do território, sobretudo na costa sul, onde se encontra a cidade do Funchal, capital da Região Autônoma da Madeira, que concentra 45\% da população, com uma densidade populacional de $1.500 \mathrm{~h} / \mathrm{km}^{2}$. 
As fortes limitações ao desenvolvimento impostas pelo meio físico explicam a elevada emigração dos naturais do território, fenômeno que diminuiu um pouco nas últimas décadas. Os principais destinos da emigração madeirense são a Venezuela, África do Sul, França, Suiça, Ithas do Canal, Estados Unidos e Brasil. ${ }^{5}$

Originalmente, os madeirenses eram agricultores e os primeiros habitantes da ilha emigraram para lá da região do Algarve. A principal atividade econômica, fora de Funchal - a capital da ilha -, era a exploração de pequenos terrenos agrícolas, cuja extensão não ultrapassava os 1 mil metros quadrados. Nas primeiras décadas do século XX, a crise econômica causada pela dependência do mercado exterior estimulou a emigração.

Atualmente, o turismo aparece como um dos destaques da economia da ilha, que apesar de tudo continua tendo uma agricultura expressiva, produzindo sobretudo frutas que são exportadas para Portugal continental e outros países da União Europeia.

\section{Os madeirenses na zona rural do município do Rio de Janeiro}

Vários imigrantes portugueses oriundos da Itha da Madeira estabeleceram-se a partir de 1920 no bairro de Campo Grande, especialmente na Serra do Mendanha, ${ }^{6}$ na região oeste da cidade do Rio de Janeiro. Nesse lugar, eles praticavam uma agricultura mais voltada para a subsistência com ênfase no plantio de hortaliças e outras culturas secundárias. A introdução da horticultura contou especialmente com a presença dos portugueses, mas nessa região

5 Depois da crise da Venezuela, vários portugueses e seus descendentes retornaram para Portugal e especialmente para a Ilha da Madeira.

6 A Serra do Mendanha é uma formação montanhosa localizada na zona oeste carioca no limite dos municípios do Rio de Janeiro e Nova Iguaçu, no estado do Rio de Janeiro. também estavam instalados alguns imigrantes japoneses e italianos.

Atualmente, a população da Serra do Mendanha é composta por famílias vinculadas, em grande parte, ao trabalho agrícola na região. Ali, habitam e trabalham pessoas de origem brasileira e de origem portuguesa - apesar de estatisticamente aparecerem como minoria, os imigrantes portugueses exercem uma influência cultural muito grande na região. Sua participação, ainda que em menor número, é bastante expressiva, principalmente, quando consideramos que, dentre esses grupos, o dos portugueses revelou uma posição socioeconômica melhor se comparada à situação dos grupos de brasileiros.

A agricultura praticada na Serra do Mendanha é baseada na horticultura, sendo o chuchu, a abóbora e o aipim os principais produtos. A produção é basicamente destinada à comercialização e, em menor escala, à subsistência. Essa composição da produção destinada ao comércio se justifica tanto pela qualidade do solo quanto da demanda imposta pelo mercado.

Ainda hoje, na Serra do Mendanha, os grupos familiares se organizam em torno de papéis sociais bem definidos: à mulher, cabem as atividades reprodutivas, e embora também trabalhe na lavoura, o seu trabalho é caracterizado como "ajuda", de forma que, hierarquicamente, perde importância em relação ao trabalho desempenhado pelos homens. Essa hierarquia se objetiva na falta de remuneração pelo trabalho e na negação aos direitos previdenciários, visto que, ao não ser reconhecida a relevância da sua participação, nega-se a identidade de trabalhadora social/legalmente constituída. Essa utilização da mão de obra feminina e infantojuvenil ocorre no contexto de reprodução familiar, no qual a figura masculina representa o chefe, o "superior".

Essa disposição dos papéis dos grupos familiares vai se repetir nos pequenos comércios 
com mão de obra familiar. A mulher e os filhos solteiros que trabalham efetivamente nessa área não costumam ter carteira de trabalho ou participação na sociedade e o seu trabalho é visto como uma "ajuda".

\section{Os relatos dos imigrantes}

Como já explicamos, optamos por entrevistar sobretudo os mais velhos. Acreditamos que os depoimentos que optamos por transcrever são paradigmáticos e, portanto, na maior parte dos casos, podem ser generalizados para todo o grupo de migrantes madeirenses no Rio de Janeiro. Os depoimentos que transcrevemos a seguir, parte de histórias de vida, nos ajudam a compreender melhor a comunidade e suas relações com a Ilha da Madeira.

Em um trecho da entrevista, podemos perceber a importância da família nos processos migratórios e também a formação de uma comunidade transnacional, à medida que os diferentes integrantes de uma mesma família migram para países distintos.

Ah! Eu tive um irmão na Venezuela, que aquele dia que eu vim pra aqui, tava um irmão mais velho do que eu um pouquinho, tava na Venezuela, e ele mandou vir pra cá e daqui do Brasil ele mandou me chamar pra ir para Venezuela. Aí ele até disse que deixasse a mulher, que eu tava namorando a minha mulher e então ele disse 'ele vai casar e ele vai pro Brasil' porque ela também tinha aqui, os irmãos. E então ela disse, vamos e depois se tu vai para Venezuela eu vou contigo...

E a minha esposa também tinha uns irmãos aí. Então eu disse que ela ficava aqui e eu ia para Venezuela. Eu tinha um irmão que mandou me chamar pra lá, que lá se ganhava mais dinheiro que aqui.

E ele já teve aqui, até com a minha esposa, ele já esteve aqui passeando. Uma ou duas vezes. Já morreu também que ele levou uma trombada de carro, numa ocasião, o carro dele, e ele... Quando a gente ia para Portugal a gente andava junto, eu e ele, a gente era muito amigo. (A.S., 81 anos, agricultor)

A família e a Venezuela voltam a aparecer em outro trecho do depoimento:

Mas, eu tô aqui, e meus filhos são com a mãe, a primeira esposa, mas teve doze anos que eu morei sozinho com eles. Teve a empregada, mas eu andava sempre mais desanimado; eu fui a Portugal, até pra trazer uma mulher de lá. Mas, sabe, Portugal, ninguém gosta de vir pro Brasil mais [...]

Ninguém. Se você diz se quer vir pro Brasil: 'não'... Lá eu arrumei uma moça até era... mas não veio. [...]

Agora não vem. Eu até falei que tinha uma prima minha lá que, tinha 40 anos, ela era solteirona e eu gostei muito. Ela que tomava conta de tudo porque ela só tinha um irmão na Venezuela e lá não tinha mais ninguém. Aí ela ainda me disse, pois eu perguntei se ela gostava de vir para aqui? Ela me disse: 'não... se fosse para outro país eu ia, mas pro Brasil, não'. Ninguém gosta. (A.S., 81 anos, agricultor)

Sobre as idas a Portugal, ele relata:

Meu lugar era lá no Estreito, era lá... eu tinha um irmão lá, ele já morreu, e eu ficava sempre em casa dele quando ele tava vivo. E eu ficava bem, eu ficava nos lugares que eu conhecia os parentes [...]. (A.S., 81 anos, agricultor)

Ou seja, apesar da migração de muitos anos para o Brasil, a Itha da Madeira continua a ser a referência, o lugar onde vai para encontrar com os parentes, "para ficar bem".

Para percebermos as questões de gênero que envolvem tanto a migração, quanto os retornos à ilha, transcrevemos agora a entrevista de (A. de 81 anos). Começamos a entrevista perguntando por que ela tinha imigrado para o Brasil:

[...] vim porque casei com um viúvo. E o viúvo morava aqui. Era desses Gomes. Manoel Gomes. E então ele só foi passear lá mesmo para arrumar família e vir. 
[...] Só que ele era de muita idade. Ele tava com cinquenta e quatro anos e eu com dezoito anos.

Só que quando me casei com ele eu estava com dezoito anos. E ele depois foi morar um pouco pra cidade... Porque naquele tempo, quem vinha pra ficar, tinha que ir para a Europa para passar o visto com o consulado brasileiro... Porque quem viesse só pra passeio não era preciso ir a Lisboa. Agora, se não fosse, se viesse pra ficar, se fosse aleijado ou qualquer coisa, aí não podia vir. Até que quando fui fazer a verificação de saúde, em Lisboa, eu tava fazendo dezenove anos naquele dia o médico que me examinou até falou: 'Que coincidência, a senhora está a fazer dezenove anos, hoje é dia dezenove e são dezenove horas'.

Então passei por Lisboa. Fiquei um mês em Lisboa, depois vim pra aqui. Depois que eu casei com ele, foi capacidade, eu viajei fui pra um hotel... quer dizer que era tudo bom. Aí quando ele falava que vinha-se pruma serra eu achava que ele tava mentindo pra mim, mas ele tava falando a verdade... Então, quer dizer que tudo era diferente: eu cheguei aqui e tudo era diferente. Tinha que ficar dentro de casa. Eu chorei muito. Quando eu cheguei eu chorei muito... (A., 81 anos) ${ }^{7}$

Observamos que, nesse caso, a migração da mulher só é possivel porque acontece para acompanhar um marido que já estava instalado no Brasil, um viúvo, com filhos, que volta para a Ilha da Madeira para buscar uma esposa.

No relato, também podemos observar a dificuldade de adaptação em uma terra estranha, longe da família e com costumes diferentes. Perguntamos se ela se arrependeu de ter vindo e a resposta foi: “Não! Ele não me maltratava...". Na continuação da entrevista, ela fala da família, do marido e dos enteados.

7 Para emigrar, era necessário uma série de papelada, nomeadamente: a carta de chamada - de pais para filhos, de filhos para pais, de maridos para mulheres -, as certidões, as consultas médicas e os primeiros documentos da Câmara. Seguiam-se as duas chamadas ao Secretariado do Governo Civil, no Palácio de São Lourenço em Funchal. E depois a ida a Lisboa para o visto. Ou seja, exigia tempo e dinheiro.
[...] ele tinha sete [filhos] menores quando casei com ele. Sete menores! Tinha já sete filhos. Naquele tempo a gente não tinha outro recurso, quantos viessem, pegava. E ele era aquele senhor que tava sempre arrumado, até mesmo para comer. Tinha fartura.

Quando a gente veio, tinha uma nora dele, morava na casa. A casa era grande, tinha, atrás, tinha três quartos, uma cozinha, e ainda tinha três em cima... e três quartos embaixo. Um era para comida dos porcos... o outro era para ferramentas e o outro era dos empregados dormirem. ${ }^{8}$

Aqui tinha conforto. Graças a Deus. Não faltava nada. Aí eu tinha um fogão de seis bocas. Uma boca era uma caverna d'água, era uma coisa que ninguém tinha igual aqui nesse lugar. (A., 81 anos)

Ou seja, um bom marido era aquele que não maltratava a mulher e tinha fartura na mesa. Mesmo que tivesse o triplo da sua idade e viesse com sete filhos. Perguntada sobre as suas idas à Ilha da Madeira e sobre a família que deixou por lá, conta que foi duas vezes antes de ficar viúva, que tem sobrinhas na ilha, mas que a maioria está na Espanha, na Suiça e tem uma na Alemanha.

Não quer voltar para a Ilha da Madeira porque seus filhos e netos estão no Brasil, os pais e os irmãos já morreram - o único que ainda está vivo também mora no Brasil -, mas diz que lá é o melhor lugar do mundo e que quando ela chegou ao Brasil chamavam a Itha da Madeira de "Pérola do Atlântico".

Percebemos que as mulheres possuíam menos autonomia tanto para a migração, quanto para a volta à Ilha. Normalmente não viajavam sozinhas, estando sempre acompanhadas pelo marido e, em alguns casos, pelos filhos mais velhos.

Nos dois casos, notamos também que o

8 Aparentemente, a entrevistada faz uma pequena confusão nesse trecho, seu marido tinha sete filhos, mas certamente nem todos eram menores porque pelo menos um deles já era casado. 
casamento preferencial é com um outro imigrante português ou com um descendente de imigrantes portugueses, especialmente no caso dos homens, já que a cultura da mãe é importante para a socialização dos filhos, há uma expectativa de que elas compartilhem os mesmos valores dos maridos. Nesse caso, a cultura é pensada enquanto produto da apropriação de um grupo social que, através dela, norteia o estabelecimento de relações políticas, afetivas, identitárias e de pertencimento.

Como em outros grupos de imigrantes, aparece aqui certa confusão entre valores camponeses e os valores do grupo imigrante, muitas das coisas que eles apontam como sendo "coisa de português" são, na realidade, típicas do campesinato: religiosidade, solidariedade, mesa farta, patriarcalismo e trabalho familiar. Pudemos notar nesse caso a incorporação e reelaboração de valores e costumes camponeses por parte de uma população urbana, em função de um apelo a uma origem portuguesa.

Os relatos transcritos neste artigo inseremse na história da vida cotidiana, nossos depoentes não são heróis, não desempenharam um papel de destaque na história mundial, mas permitem que enxerguemos melhor as questões migratórias, possibilitam o entendimento da importância da família nas redes de migração e da relevância de motivos não econômicos para a tomada de uma decisão - tão radical como essa de mudar de país, de continente e se arriscar em um país desconhecido.

Os depoimentos também permitem perceber como a imigração não corta os laços com a terra natal, o local de origem e aqueles que ficaram nele, mas desempenham um papel importante no sentido de servir de referência para aqueles que partiram, funcionando como o local do encontro e da partilha.

Por fim, cabe destacar que a identidade de madeirenses é construída no contexto histórico da migração, já que não haveria sentido para os grupos se identificarem a partir de certos elementos culturais próprios e diferenciados se não houvesse um conjunto de outros em contraposição, ou seja: identificar-se como grupo é diferenciar-se em relação a outros grupos. ${ }^{9}$

\section{Considerações finais}

Observamos que se as autobiografias se preocupam muito com o depoimento, e o exemplo, para a posteridade, nas histórias de vida, talvez por serem orais e geralmente produzidas por solicitação do pesquisador, o que predomina é a noção de trajetória nos termos de Bourdieu (1986). Nossos entrevistados nos contaram histórias de uma trajetória que começa na Ilha da Madeira e acaba no Rio de Janeiro.

Todavia, os espaços se sobrepõem: o local, o regional e o nacional. Frequentemente se toma o todo pela parte. A Madeira é Portugal e Portugal é a Madeira. Da mesma forma, a Madeira é o Estreito de Câmara dos Lobos e a casa dos parentes. Por outro lado, é na Madeira que se reúnem irmãos que moram em países diferentes como Brasil e Venezuela. É na Madeira que encontram os primos que hoje moram na Suiça e na Alemanha. Ou seja, a trajetória é circular, volta-se frequentemente ao ponto de partida, nem que seja apenas na memória.

\section{Referências}

BARTH, Fredrik. Towards greater naturalism in conceptualizing societies. In: A. Kuper (Ed.) Conceptualizing Society, London: Routledge, 1992. p. 17-33.

9 Utilizamos o conceito de identidade como explicitado por Bauman (2005), para quem o conceito de identidade é uma entidade abstrata, virtual e sem existência concreta. Construir identidade para Bauman significa um processo de classificação e reclassificação dos grupos em categorias socialmente construidas a partir de determinados elementos culturais, tomados como referência pelo grupo em relação a outro(s) grupo(s), tais como: língua, raça, nação, religião, ritos, símbolos etc. 
BASSANEZI, Maria S.C. Beozzo. Imigrações Internacionais no Brasil: um panorama histórico. In: PATARRA, Neide (Coord.) Emigração e Imigração Internacionais no Brasil Contemporâneo. V.1, São Paulo: FNUAP, 1995.

BATTISTEL, Arlindo I.; COSTA, Rovílio. Assim vivem os italianos. Vida, história, cantos, comidas e estórias. Porto Alegre/Caxias do Sul: EST/EDUCS, 1982.

BAUMAN, Zygmunt. Identidade: entrevista a Benedetto Vecchi. Rio de Janeiro: J. Zahar, 2005.

BERTAUX, Daniel. Los Relatos de Vida. Barcelona: Edicions Belaterra, 2005.

BOURDIEU, Pierre. L'illusion biographique. In: Actes de la recherche en sciences sociales. Vol. 62-63, 1986. p. 69-72.

BRAUN, Felipe Kuhn. Memórias de Imigrantes Alemães e seus descendentes no Sul do Brasil. Nova Petrópolis: Amstad, 2010.

CARVALHO, Isabel Cristina Moura. Biografia, identidade e narrativa: elementos para uma análise hermenêutica. Horizontes antropológicos, Porto Alegre, v. 9, n. 19, July 2003, p. 283-302.

CONDE, Idalina. Problemas e virtudes na defesa da biografia. Sociologia, problemas e práticas, n. 13, 1993, p. 39-57.

COSTA LEITE, Joaquim da. O Brasil e a Emigração Portuguesa (1855-1914). In: FAUSTO, Boris (org.) Fazer a América. São Paulo: EDUSP, 2000.

DELGADO, Lucília de Neves. História oral - Memória, tempo, identidades. Autêntica Editora, 2007.

DEMARTINI, Zeila de Briro Fabri. Imigração e educação: os portugueses em São Paulo no início do século XX. Cadernos CERU, série 2, n. 12, 2001, p. 161169.

DUMONT, L. Essays on individualism: modern ideology in Anthropological perspective. Chicago, USA: University of Chicago Press, 1992.

FAUSTO, Bóris. Negócios e ócios. São Paulo: Companhia das Letras, 1997.

FOOTE WHYTE, William. Sociedade de Esquina. Rio de Janeiro. Jorge Zahar Editor, 2005.

FREITAS, Sônia. História oral: possibilidades e procedimentos. São Paulo: Humanitas; I.O.E., 2002.

GILLIS, John R. Memory and identity: the history of a relationship, In: IDEM (ed.). Commemorations: the politics of national identity. New Jersey: Princeton University Press, 1994.

HOBSBAWM, Eric. Introdução: a invenção das tradições. In: HOBSBAWM, Eric; RANGER, Terence (Org.). A invenção das tradições. Rio de Janeiro: Paz e Terra, 1997. p. 9-23.

LEVY, Maria Stella Ferreira. O papel da migração internacional na evolução da população brasileira (1872-1972). Revista de Saúde Pública, São Paulo, v. 8, supl. 0, 1974.

MAUSS, Marcel. Uma categoria do espírito humano: a noção de pessoa e a de "eu". In: MAUSS, Marcel. Sociologia e Antropologia. São Paulo, Cosac Naify, 2003. p. 369-397.

MENEZES, Lená Medeiros. Jovens Portugueses: Histórias de Trabalho, histórias de sucessos, histórias de fracassos. In: GOMES, Ângela de Castro. Histórias de Imigrantes e de imigração no Rio de Janeiro. RJ: 7 letras, 2000. p. 164-182.

NEVES, Lúcia Maria B. P.; FERREIRA, Tânia Maria T. B. Portugal, França e Brasil: representações imaginadas (1808-1914). In: MENEZES, Lená Medeiros; ROLLEMBERG, Denise; MUNTEAL FILHO, Oswaldo. Olhares sobre o político. RJ: Eduerj, 2002. p. 27-46

NORA, Pierre. Entre memória e história: a problemática dos lugares. Projeto História. São Paulo: PUC-SP. n. 10, 1993, p. 7-26

POLLAK, Michael. Memória e Identidade Social. In: Estudos Históricos, Rio de Janeiro, v. 5, n. 10, 1992, p. 200-212.

SANTOS, Miriam de Oliveira. A noção de identidade e seu uso nos estudos migratórios. REMHU: revista interdisciplinar da mobilidade humana, Brasília, v. 18, n. 34, jun. 2010, p. 27-43.

SAYAD, Abdelmalek. A Imigração. São Paulo: Edusp, 1998. 
SEYFERTH, Giralda. A dimensão cultural da imigração. Revista brasileira de Ciências Sociais. v. 26, n. 77, 2011, p. 47-62.

SILVA, Douglas Mansur da. A Oposição ao Estado

Novo no Exílio Brasileiro (1956-1975). 1ạ Ed. Lisboa: Imprensa de Ciências Sociais, 2006.
THOMAS, William I.; ZNANIECKI, Florian. The Polish peasant in Europe and America. New York: Octagon Books, 1974.

Recebido em: 21/01/2020

Revisado em: 29/07/2020

Aprovado em: 30/08/2020

Miriam de Oliveira Santos é doutora em Antropologia Social pela Universidade Federal do Rio de Janeiro (UFRJ), mestre em Ciência Política pela Universidade Federal do Rio Grande do Sul (UFRGS) e licenciada em Ciências Sociais pela Universidade do Estado do Rio de Janeiro (UERJ). É docente na Universidade Federal Rural do Rio de Janeiro (UFRRJ), vice-coordenadora do Núcleo Interdisciplinar de Estudos Migratórios (NIEM) e investigadora colaboradora no Research Centre for Tourism, Sustainability and Well-being (CinTurs) da Universidade do Algarve.E-mail: mirsantos@uol.com.br 